Crit Rev Phys Rehabil Med. 2012 ; 24(3-4): 251-264. doi:10.1615/CritRevPhysRehabilMed.2013007630.

\title{
Osteoarthritis: A Critical Review
}

\author{
Kentaro Onishi ${ }^{1,{ }^{*}}$, Amol Utturkar ${ }^{1}$, Eric Chang ${ }^{1,2}$, Richard Panush $^{3}$, Justin Hata ${ }^{2}$, and \\ Danielle Perret-Karimi ${ }^{2}$ \\ ${ }^{1}$ Department of Physical Medicine and Rehabilitation, University of California—Irvine, Orange, \\ California \\ 2Division of Pain Medicine, Department of Anesthesiology and Perioperative Care, University of \\ California-Irvine, Orange, California \\ ${ }^{3}$ Department of Medicine, University of Southern California, Keck School of Medicine, Los \\ Angeles, California
}

\begin{abstract}
Patients with osteoarthritis (OA) are faced with a barrage of treatment options, from recommendations from friends and social media to medications prescribed by the primary care physician. The purpose of this article is to critically review current approaches to generalized or monoarticular OA based on available evidence and to illustrate multidisciplinary and multimodal treatment strategies for the management of OA. Treatment options assessed for efficacy include patient education; oral and topical pharmacological agents; complementary and alternative medicine; surgery; manual medicine; acupuncture; interventional procedures (corticosteroid injection, viscosupplementation, and pulsed radiofrequency); bracing; assistive devices; physical therapy; and physical modalities. Multidisciplinary and multimodal treatment strategies combined with early detection and prevention strategies provide the best benefit to patients.

This review also illustrates that traditional and alternative modalities of treatment can be both synergistic and beneficial. Physicians should be aware of the variety of tools available for the management of OA and the associated symptoms. Those healthcare providers who can best individualize treatment plans for specific patients and inspire their patients to embrace healthy lifestyle modifications will achieve the best results.
\end{abstract}

\section{Keywords}

degenerative joint disease; physical therapy; complementary medicine; pulsed radiofrequency; corticosteroid; viscosupplementation; hyarulonic acid; arthroscopy brace; joint replacement

\section{PATHOLOGY OF OSTEOARTHRITIS}

Current practice solutions in osteoarthritis (OA) have come a long way: from dismissing OA as a phenomenon of inevitable degeneration to acknowledging its etiology, prevalence, symptomatology, and limitations on physical function in modern times. OA continues to be

*Please address all correspondence to: Kentaro Onishi, DO, Department of Physical Medicine and Rehabilitation, UC Irvine, 12441 Old River School Rd Apt 209, Downey, CA 90242; kenonishi918@gmail.com. 
the most common joint disorder in the world, and many patients remain undiagnosed. As a disorder labeled "wear and tear," the consequences of OA will certainly continue to rise as the population ages and as the percentage of the workforce older than 65 years of age increases. Not only does symptomatic OA cause chronic pain and diminish quality of life, it can also add a distinct emotional component to the functional disability experienced. Pain and stiffness plague patients with OA. OA-related pain is challenging to treat because it is generated via a multitude of both inflammatory and mechanical nociceptive conduits. There is growing speculation that secondary peripheral, spinal, and supraspinal neuropathic pain mechanisms may also be activated. Recent research also has revealed that changes in almost all periarticular tissues are part of the spectrum of this disease. ${ }^{1}$ Classic osteophytosis and subchondral degeneration are coupled with pathology of the spongy bone, synovium, synovial fluid, cartilage and periarticular bursae, ligaments, and myofascial structures, all of which can be significant. In some patients the sensory nerve fibers may also display pathology due to various direct and indirect factors. ${ }^{2}$

\section{CURRENT STRATEGIES IN THE TREATMENT OF OSTEOARTHRITIS}

\section{A. Lifestyle Modifications}

Because of the multitude of pain generators and nociceptive mechanisms involved in the propagation of $\mathrm{OA}$, it is unlikely that a single treatment modality will target the entirety of the disease process. A multimodal approach utilizing conservative nonpharmacologic therapy followed by pharmacologic therapy is suggested. According to recent American College of Rheumatology guidelines, ${ }^{3}$ nonpharmacologic therapies are mandatory in all patients, even if pharmaceuticals are prescribed. Educating patients and providing recommendations for realistic lifestyle modifications are also important in the management of OA.

It is our opinion that the treatment of osteoarthritis starts with lifestyle changes before prescribing medication and nonpharmacological therapies. Weight loss is important in reducing symptoms as well as for palliating the progression of OA in weight-bearing joints such as the knee and hip. Modest weight reduction using proper diet and exercise routines should be stressed in overweight patients. ${ }^{4}$ Periodic monitoring for compliance is important, and referrals to weight loss programs may be used to improve compliance. Sleep hygiene, regular exercise, smoking cessation, and moderate consumption of alcohol are all recommended for general health. These lifestyle modifications may sound like common sense; however, they may be more challenging to patients than simply taking a pill and going to see a therapist.

\section{B. Traditional Pharmacotherapy}

Oral medications traditionally have been important to control pain in OA. To date, no drugs with significant disease-modifying properties have emerged. In the contemporary management of OA, oral agents are used primarily for analgesia. Multiple studies and guidelines recommending the approach to oral analgesia have been published over the years. Many trials comparing various medications also have been published in the literature. ${ }^{3}$ Acetaminophen is the first-line oral agent in $\mathrm{OA}$ and is chosen for its effectiveness against 
mild to moderate pain as well as its low side effect profile. ${ }^{5}$ New guidelines suggest keeping the total daily dose to less than $3 \mathrm{~g}$ to avoid hepatotoxicity. Recent literature supports the idea that there is an inflammatory component to OA, and oral nonsteroidal antiinflammatory drugs (NSAIDS) also are commonly used. There does not seem to be a difference among the various drugs in this class, but side effects can be significant: gastrointestinal mucosal bleeding and renal disease are the main limiting factors, especially in the elderly. Cyclooxygenase-2 selective inhibitors are equal in efficacy compared to nonselective NSAIDS and may have superior gastrointestinal side effect profiles, although they may have increased risk of cardiac complications such as ischemia and myocardial infarction compared to nonselective NSAIDS. ${ }^{6,7}$ When the pain becomes moderate to severe and refractory with other medications, the opiate class of analgesics are typically used for analgesia. ${ }^{8}$ These drugs often are combined with acetaminophen for a synergistic effect and are available in various potencies. Nonnarcotic agents, such as the weak $\mu$-agonist tramadol, are sometimes tried before starting opioids. ${ }^{9}$ Side effects such as sedation, nausea, constipation, hypotension, development of tolerance, and apnea can be significant with chronic narcotic use. Patients must be selected and monitored carefully when using these medications, especially the elderly and those with a history of substance abuse. Muscle relaxants can be used adjunctively for secondary muscle spasm and can provide a modest analgesic effect. New evidence for the activation of neuropathic nociceptive pathways in OA suggests possible future use of adjunctive neuropathic agents such as calcium channel blockers, anticonvulsants, $\mathrm{N}$-methyl-d-aspartate antagonists, and certain antidepressants. ${ }^{10}$

Numerous studies have documented the efficacy of topical NSAIDS in mild to moderate OA of the knee, hand, and other easily accessible areas. ${ }^{11,12}$ Some guidelines recommend the use of topical NSAIDS before prescribing their oral equivalents. ${ }^{13,14}$ Topical agents have the advantage of avoiding systemic side effects and can target a single symptomatic area. According to the literature, topical NSAIDS have greater efficacy compared with topical capsaicin, salicylates, and analgesics, such as menthol, as well as local anesthetics, although all these agents have been used with positive results. ${ }^{15}$ Topical delivery of medication to a small area limits its use in diffuse disease.

\section{Complementary Alternative Medicine and Naturopathic Pharmacotherapy}

A number of patients prefer to avoid traditional pharmaceuticals and interventional procedures. These patients are drawn to popular complimentary and alternative therapies, which include chondroitin, glucosamine, collagen, plant-derived substances (i.e., phytotherapy), vitamins, antioxidants, ayurvedic medicine, traditional Chinese medicine, and homeopathic preparations. However, few randomized controlled trials have been conducted with these therapies, and the possibility of drug-drug interactions have yet to be fully investigated. ${ }^{16-19}$ More research is warranted in this area until the role of each can be established.

Another treatment often grouped in the above category is acupuncture. Acupuncture has been applied in various traditional and modified forms in the nonpharmacological treatment of OA. Randomized controlled trials comparing acupuncture, sham acupuncture, and routine 
care in patients with OA revealed a modest pain-relieving effect, but this diminished with time and lasted no longer than 6 months. ${ }^{20,21}$

\section{Orthotics and Assistive Devices}

New treatment guidelines suggest the use of nonpharmacologic therapy before instituting medications. ${ }^{3}$ Braces (orthotics) and assistive aids have been used for centuries and are now being utilized with increasing frequency in patients with OA. Bracing reduces pain by limiting excessive painful motion around a joint. A 2009 Cochrane review concluded that using a knee neoprene sleeve, insoles, or lateral wedge orthotics mildly improved knee pain and a knee brace improved walking distance at 6 months. ${ }^{22}$ Unloader knee braces also were found to be beneficial in reducing pain and improving physical function in patients with $\mathrm{OA}$ of the knee. ${ }^{23}$ Hand splints such as the thumb spica splint have been shown to reduce pain scores at 12 months for OA at the base of the thumb. ${ }^{24}$ Soft cervical collars and lumbosacral corsets have been used for spinal OA; more rigid bracing is generally not used in spinal OA. Although controversial, the idea that chronic bracing may lead to disuse atrophy of joint stabilizing muscles and may eventually be detrimental to joint biomechanics is common; therefore, a concurrent exercise program is often recommended. Side effects are usually related to fitting and local reaction to the materials used in fabrication.

Assistive devices are used to reduce the load on weight-bearing joints such as the knee and hip. These devices may be used as an alternative to, or complementary to, medications and potentially costly interventions. A single-point cane held in the contralateral hand is useful in knee and hip OA and may reduce disease progression in OA of the knee. ${ }^{25}$ Front-wheeled walkers ("rollators") are used to relieve symptoms of neurogenic claudication in lumbar spinal stenosis by accommodating the user to a more flexed posture. Crutches and offloading boots are generally not used in patients with OA but may be considered in special cases.

\section{E. Physical Therapy}

Exercise is considered by many to be the most important maintenance therapy for chronic $\mathrm{OA}$ and should be encouraged in all patients. Physiotherapy/physical therapy is the science of using specific exercises to strengthen joint-stabilizing muscles as well as applying therapeutic modalities to aid in healing tissues. These allow improved joint biomechanics and gait, thereby relieving pain and preventing joint dysfunction. The short-term effects of in-office physiotherapy on OA have been well proven. ${ }^{26}$ After completion of a therapistsupervised course, the patient is given an individual home exercise program (HEP) that should be performed regularly. One long-term, prospective, multicenter study in the Netherlands followed 200 patients for 60 months after discharge from physiotherapy. ${ }^{27}$ This study demonstrated that the benefit of pain control and functional preservation derived from continued HEPs are largely dependent on the adherence of the patients but remains evident 24-60 months after discharge from physiotherapy (when compared with those who did not adhere to the regimen). ${ }^{27,28}$ In contrast to more passive forms of treatment, exercise allows the patient to take a proactive role in the management of the disease. Some studies have compared the effect of physiotherapy with that of other treatment options. One prospective study involving 106 patients with OA of the knee compared 6-month outcomes of intra- 
articular hyaluronate injection and HEP and concluded that HEP offers advantages over hyaluronate injection: pain and function at the end of each intervention was equal, while HEP offered advantages in cost, invasiveness, and convenience for the patients. ${ }^{29}$

\section{F. Physical Modalities}

Physical modalities are noninvasive, time-honored approaches to pain and should be considered for OA. The most common are heating and cooling modalities. Heating can be superficial (heat packs or compresses) or deep (ultrasound, diathermy, microwave, laser) and is delivered via conduction (conventional heat packs), convection (whirlpool, baths, paraffin), or conversion (radiant heat). Therapeutic cold has an anti-inflammatory and primary analgesic effect and is excellent for reducing acute inflammation and slowing down the speed of nerve conduction. Heat relieves pain via a relaxation effect of the tissues as it is thought to increase collagenase activity. However, heat can cause vasodilation and may worsen inflammation. Limitations to the use of heat and cold modalities include neuropathic sensory loss, metallic foreign bodies or implants, certain surgical procedures, and temperature-sensitive hematologic or rheumatologic conditions. Transcutaneous electrical nerve stimulation is thought to block pain signals at the dorsal root neurons via the gate theory (by stimulating large vibration and/or pressure sensation fibers). One multicenter study found that transcutaneous electrical nerve stimulation reduced oral analgesic use in patients with OA of the knee. ${ }^{30}$ Peripheral joint or spinal traction is not known to have a direct effect on any of the known primary pathological mechanisms of OA.

\section{G. Manual Medicine/Manipulation Therapy}

Manual medicine or manipulation is employed to improve alignment and allow the body to utilize its self-healing capabilities. Manipulation has been described in the treatment of acute pain such as spinal facet sprain and muscular strains, but there remains a paucity of data in the literature on its long-term efficacy in chronic arthritic pain. Manipulation is postulated to act directly on the affected tissues or indirectly through neurological or vascular mechanisms. More research is warranted to explore this method of treatment.

\section{H. Interventional Therapy}

1. Traditional Injection Therapy-Intra-articular joint injections and procedures are a popular modality used to deliver medications directly into the joint space or to aspirate an acutely inflamed joint. Intra-articular injections were first described in the 1930s in Pemberton's textbook, Arhtirits and Rheumatoid Conditions: Their Nature and Treatment. ${ }^{31}$ In the 1950s, more publications focused on the benefits of analysis of fluid from the joints; this further popularized the idea of intra-articular needle placement. ${ }^{32}$ Among multiple reagents tried in these earlier times (formalin, glycerin, lactic acid), corticosteroid injection provided the most meaningful symptomatic relief for joint pain. Today, corticosteroid injections (although not without controversy and potential side effects) and viscosupplementation are common intra-articular procedures performed for symptomatic relief of painful OA. Aspiration and needle placement for injections are generally conducted using a blind or anatomic approach but may be conducted under ultrasound or fluoroscopic guidance if the approach is difficult (as in an obese patient) or if visual confirmation is 
desired for added accuracy. One pilot study that popularized the use of musculoskeletal ultrasound (MSK US) was published in 2002 and compared the accuracy of needle placement using blind joint aspiration ( $\mathrm{n}=32$ joints) versus MSK US-guided aspiration $(\mathrm{n}=$ 31 joints). In this study, the blind joint aspiration group received successful aspiration (confirmed by ultrasound after aspiration) 32\% of the time as opposed to 97\% in MSK USguided group. ${ }^{33}$ Another study demonstrated similar results with smaller joints. Researchers compared the accuracy of needle placement using the blind method versus the MSK USguided method on proximal interphalangeal joints and metacarpophalangeal joints and concluded that MSK US provided much higher accuracy for needle placement in small joints. ${ }^{34}$ Finally, there are multiple studies that have shown evidence of increased needle placement accuracy via MSK US by inexperienced trainees. A randomized, double-blind, controlled study involving 184 patients demonstrated that an inexperienced rheumatologist using MSK US-guided injections had higher accuracy for needle placement than that of an experienced, senior rheumatologist without ultrasound guidance; multiple joints—shoulders, knees, ankles, wrists, and elbows—-were included in the study. ${ }^{35}$

The initial intra-articular corticosteroid injection by Hollander et al. ${ }^{36}$ in the 1950 s used hydrocortisone acetate. Today there is geographical variability in choice of injectate; corticosteroids are sometimes coupled with local anesthetics. According to a survey conducted by American College of Rheumatology, methylprednisolone and triamcinolone are popular choices because of reports of less pain after injection. ${ }^{37}$ The current standard of practice for the frequency of recommended corticosteroid injections is one injection every 3 months to avoid theoretic risks of steroid-induced deterioration of intra-articular cartilage, among other effects.

Viscosupplementation involves intra-articular injections of hyaluronate, which is derived from naturally occurring glycosaminoglycan molecules. There are currently 5 formulations approved by the US Food and Drug Adnimistration (Euflexxa, Hyalgan, Synvisc, Supartz, and Orthovisc). All of these are indicated for symptomatic mild to moderate OA refractory to oral analgesics and other conservative measures. The only significant contraindication is known history of severe allergic reaction to hyaluronate or its components. Frequency of indication is dependent on the formulation. Pioneered by Balzas, ${ }^{38}$ viscosupplements have been well tolerated and efficacious in the treatment of OA of the knee. A 2006 Cochrane review revealed up to 54\% pain relief in patients receiving viscosupplements, with the effect most pronounced 5 to 13 weeks after injections. ${ }^{39}$ Viscosupplementation has been employed, albeit off-label, to treat other joints, such as the ankle and hip, with symptomatic relief reported in observational studies; however, significant randomized controlled data remains scarce. ${ }^{40,41}$ Compounds with a higher molecular weight may offer better symptomatic relief in both the short term ( 3 months after injection) as well as the long term (6 months after injection). ${ }^{42}$ When corticosteroid and viscosupplementation treatments are compared, one study suggests that better short-term relief is provided by corticosteroid injection (at 4 weeks after treatment) but that better long-term relief is provided by viscosupplementation (from weeks $8-26$ ). ${ }^{43}$

2. Empirical Interventional Therapy-Pulsed radiofrequency (PRF) neuromodulation is a treatment modality under investigation that may be considered for the management of 
OA refractory to more traditional options. This technique uses nonablative radiofrequency energy targeted to either intraarticular neural structures within the joint or to the extraarticular sensory nerves. The intra-articular approach typically targets its radiofrequency waves at the articular periosteal surfaces to modulate nociceptive input via changes in cellular genetics and metabolism. One case series documents intra-articular PRF to manage refractory OA pain at 6 heterogenic body parts, including the cervical facet, knee, sacroiliac, radiocarpal/scapholunate, shoulder, and atlantoaxial joints. All patients in this series reported reduced pain as expressed by subjective improvement of function, visual analogue scale (VAS) score, or other means of outcome measures. ${ }^{44}$ Notably, pain was well managed in these 6 cases up to 12 months after the procedures. As an alternative, sensory nerves can be targeted extra-articularly to alter the innervation to the joint and effectively reduce nociceptive output from the arthritic joints. This technique has been frequently documented as a viable option for treatment of arthritis pain in the shoulders and hips. In 2002, Rohof ${ }^{45}$ first treated 37 patients with chronic shoulder pain using PRF of the suprascapular nerve. While no etiologic diagnosis for these patients was reported in this original article, the subjects reported on average a 4.5-point reduction on a 10-point pain scale after the procedure. Shah and Racz ${ }^{46}$ treated a patient with adhesive capsulitis and OA with a course of 4 PRF sessions over 16 months, with 3 months of symptomatic relief for. Liliang et al. ${ }^{47}$ published a study of 13 chronic painful shoulders that had decreased pain level and decreased disability index 6 months after suprascapular nerve radiofrequency. In $2007 \mathrm{Wu}$ and Groner ${ }^{48}$ reported 2 cases of hip pain that were successfully treated with PRF. The patients reported a significant reduction in pain, with improved function for 3-4 months after PRF targeted to the articular branches of femoral and obturator nerves. There are several limitations of PRF as a treatment option, including limited evidence based on observational data alone and limited insurance coverage.

\section{Surgical Treatments}

Types of traditionally performed surgical procedures for OA are (1) arthroscopic procedures, (2) decompressive procedures, (3) arthrodesis (surgical fusion as in the carpal bones), (4) osteotomy, and (5) partial or total joint arthroplasty.

1. Arthroscopic Procedures-Arthroscopic procedures involve joint irrigation/lavage with normal saline. The efficacy of arthroscopy, however, is still controversial. ${ }^{49,50}$ Another component of arthroscopic procedures is debridement, which is known to be beneficial when $\mathrm{OA}$ is associated with the radiographic finding of an intra-articular loose body. ${ }^{51}$ Other arthroscopic procedures include arthroscopic abrasion of sclerotic bones, for which there is limited data. A study conducted by the Mayo Clinic in Cleveland, Ohio, did not demonstrate predictable results: a third of the patients improved with the procedure, whereas a third worsened and a third had no change in symptoms before and after the operation. ${ }^{52}$

2. Decompressive Procedures-In the spinal canal, the impingement of nerves caused by degeneration and subsequent overgrowth of bone may occur (typically causing spinal stenosis or foraminal stenosis), resulting in pain, paresthesias, and potential sensory and/or motor dysfunction. In an effort to alleviate pain caused by spinal stenosis, interventional 
pain management techniques or decompressive surgical procedures can be employed to alleviate nerve impingement or create space in the spinal canal. ${ }^{53}$

3. Arthrodesis-Arthrodesis has largely fallen out of favor for large joints because of its subsequent limitation in range of motion, such as in the hips or knees, in light of the higher success rate of current arthroplasty procedures. However, fusion still plays a role in treatment of OA of smaller joints, such as in the hands, feet, and ankles. Spinal fusion surgery may correct instability from multilevel decompressive spine surgery. Tibiotalar joint fusion, often following trauma resulting in tibiotalar OA, and carpometacarpal joint fusion/ arthrodesis are the most commonly performed fusion surgeries. ${ }^{54}$ In a young, active patient with early OA of the ankle joint, arthrodesis of the tibiotalar joint should be considered as a treatment option. These procedures recently have been performed arthroscopically.

4. Osteotomy-Osteotomy, particularly the technique known as high tibial osteotomy, has been employed as a successful treatment option for unicompartmental OA of the medial knee in younger (usually $<60$ years old) active patients. In this procedure, a wedge is taken out of the tibia to relieve unequally distributed weight bearing (patients with varus deformity of the knees) over arthritic joint surfaces. However, osteotomy may have only temporary effects. ${ }^{55}$

5. Joint Replacement-The most commonly performed surgical procedures for OA in large joints are arthroplasties or joint replacements. Current U.S. estimates count 150,000 hip arthroplasties and 300,000 total knee arthroplasties per year. ${ }^{56}$ It should be noted that the success rate and complication rate for the replacements have strong correlations with the numbers of cases performed by an individual surgeon and with the volume of cases seen at a hospital. One recent study demonstrated a higher functional outcome 2 years postoperatively and a lower risk of postoperative complications with higher numbers of cases per surgeon/ hospital. ${ }^{57}$ Indications for total hip and knee arthroplasties include failure of conservative treatment options with debilitating pain and a significant decrease in function (mobility or activities of daily living). Contraindications to both knee and hip replacements include active infection, poor vascular supply, poor dentition, and poor sensation. Outcomes of total joint arthroplasty are rather dramatic, with extremely high success rates in relieving pain for more than 10-15 years postoperatively; pain relief occurred in more than $90 \%$ of the cases in one study http://www.ncbi.nlm.nih.gov/pubmed/8156309. High rates of patient satisfaction also have been noted in several studies ${ }^{58,59}$ For refractory end-stage OA of the knees or hips, arthroplasty is an excellent treatment option, when appropriate.

\section{SUMMARY}

OA involves complex changes around the affected joints, including structural, biomechanical, chemical, and associated functional and neurological changes. OA remains a fascinating entity in that we continue to uncover more pathophysiology of the disease.

However, to date, medicine has not discovered a definitive treatment for OA. The fact that $\mathrm{OA}$ is generally progressive and that no cure exists can be frustrating to patients, families, and healthcare providers. 
Multidisciplinary and multimodal treatment strategies, combined with early detection and prevention strategies, provide the best benefit to patients. In addition, we are now able to appreciate that traditional and alternative modalities of treatment can be both synergistic and beneficial. Physicians should be aware of the variety of tools available for the management of OA and the associated symptoms. Those healthcare providers that can best individualize treatment plans for specific patients and inspire their patients to embrace healthy lifestyle modifications will achieve the best results (see Appendices 1 and 2).

\section{ABBREVIATIONS}

$\begin{array}{ll}\text { HEP } & \text { home exercise program } \\ \text { MSK US } & \text { musculoskeletal ultrasound } \\ \text { NSAID } & \text { nonsteroidal anti-inflammatory drug } \\ \text { OA } & \text { osteoarthritis } \\ \text { PRF } & \text { pulsed radiofrequency }\end{array}$

\section{REFERENCES}

1. Pelletier JP, Martel-Pelletier J, Abramson SB. Osteoarthritis, an inflammatory disease: potential implication for the selection of new therapeutic targets. Arthritis Rheum. 2001; 44:1237-1247. [PubMed: 11407681]

2. Dieppe PA, Lohmander LS. Pathogenesis and management of pain in osteoarthritis. Lancet. 2005; 365:965-973. [PubMed: 15766999]

3. Altman, RDHM.; Moskowitz, RW.; Schnitzer, TJ. American College of Rheumatology Subcommittee on Osteoarthritis Guidelines. recommendations for the medical management of osteoarthritis of the hip and knee. 2000. Available from: http://www.rheumatology.org/ publications/ar/2000/sep.asp

4. Miller GD, Nicklas BJ, Davis C, Loeser RF, Lenchik L, Messier SP. Intensive weight loss program improves physical function in older obese adults with knee osteoarthritis. Obesity (Silver Spring). 2006; 14:1219-1230. [PubMed: 16899803]

5. Flood J. The role of acetaminophen in the treatment of osteoarthritis. Am J Manag Care. 2010; 16(Suppl Management):S48-S54. [PubMed: 20297877]

6. Singh G, Fort JG, Goldstein JL, Levy RA, Hanrahan PS, Bello AE, Andrade-Ortega L, Wallemark C, Agrawal NM, Eisen GM, Stenson WF, Triadafilopoulos G. Succes-I Investigators. Celecoxib versus naproxen and diclofenac in osteoarthritis patients: SUCCESS-I Study. Am J Med. 2006; 119:255-266. [PubMed: 16490472]

7. Wiesenhutter CW, Boice JA, Ko A, Sheldon EA, Murphy FT, Wittmer BA, Aversano ML, Reicin AS. Protocol 071 Study Group. Evaluation of the comparative efficacy of etoricoxib and ibuprofen for treatment of patients with osteoarthritis: a randomized, double-blind, placebo-controlled trial. Mayo Clinic Proc. 2005; 80:470-479.

8. O'Neil CK, Hanlon JT, Marcum ZA. Adverse effects of analgesics commonly used by older adults with osteoarthritis: focus on non-opioid and opioid analgesics. Am J Geriatr Pharmacother. 2012; 10:331-342. [PubMed: 23036838]

9. Gana TJ, Pascual ML, Fleming RR, Schein JR, Janagap CC, Xiang J, Vorsanger GJ. 023 Study Group. Extended-release tramadol in the treatment of osteoarthritis: a multicenter, randomized, double-blind, placebo-controlled clinical trial. Curr Med Res Opin. 2006; 22:1391-1401. [PubMed: 16834838]

10. Joshi, GP. Medscape Education Rheumatology. New York: Medscap LLC; 2010 Oct 29. Fundamentals of osteoarthritis pain: pathophysiology and pharmacologic management. Available from: http://www.medscape.org/view-article/730632. [cited 2013 Jun 3] 
11. Grace D, Rogers J, Skeith K, Anderson K. Topical diclofenac versus placebo: a double blind, randomized clinical trial in patients with osteoarthritis of the knee. J Rheumatol. 1999; 26:26592663. [PubMed: 10606379]

12. Biswal S, Medhi B, Pandhi P. Longterm efficacy of topical nonsteroidal antiinflammatory drugs in knee osteoarthritis: metaanalysis of randomized placebo controlled clinical trials. J Rheumatol. 2006; 33:1841-1844. [PubMed: 16960944]

13. Zhang W, Doherty M, Arden N, Bannwarth B, Bijlsma J, Gunther KP, Hauselmann HJ, HerreroBeaumont G, Jordan K, Kaklamanis P, Leeb B, Lequesne M, Lohmander S, Mazieres B, MartinMola E, Pavelka K, Pendelton A, Punzi L, Swoboda B, Varatojo R, Verbruggen G, ZimmermannGorska I, Dougados M. EULAR Standing Committee for International Clinical Studies Including Therapeutics (ESCISIT). EULAR evidence based recommendations for the management of hip osteoarthritis: report of a Task Force of the EULAR Standing Committee for International Clinical Studies Including Therapeutics (ESCISIT). Ann Rheum Dis. 2005; 64:669-681. [PubMed: 15471891]

14. NICE clinical guidelines 59. London: National Institute for Health and Clinical Excellence (NICE); 2008 Feb. Osteoarthritis: the care and management of osteoarthritis in adults. Available from: http://www.nice.org.uk/nicemedia/pdf/CG59NICEguideline.pdf. [cited 2013 Jun 3]

15. Cheng DS, Visco CJ. Pharmaceutical therapy for osteoarthritis. PM R. 2012; 4(5 Suppl):S82-S88. [PubMed: 22632707]

16. Tillu A, Tillu S, Vowler S. Effect of acupuncture on knee function in advanced osteoarthritis of the knee: a prospective, non-randomised controlled study. AcupunctMed. 2002; 20:19-21.

17. Mazières B, Hucher M, Zaïm M, Garnero P. Effect of chondroitin sulphate in symptomatic knee osteoarthritis: a multicentre, randomised, double-blind, placebo-controlled study. Ann Rheum Dis. 2007; 66:639-645. [PubMed: 17204566]

18. Herrero-Beaumont G, Ivorra JA, Del Carmen Trabado M, Blanco FJ, Benito P, Martin-Mola E, Paulino J, Marenco JL, Porto A, Laffon A, Araújo D, Figueroa M, Branco J. Glucosamine sulfate in the treatment of knee osteoarthritis symptoms: a randomized, double-blind, placebo-controlled study using acetaminophen as a side comparator. Arthritis Rheum. 2007; 56:555-567. [PubMed: 17265490]

19. De Silva V, El-Metwally A, Ernst E, Lewith G, Macfarlane GJ. Evidence for the efficacy of complementary and alternative medicines in the management of osteoarthritis: a systematic review. Rheumatology (Oxford). 2011; 50:911-920. [PubMed: 21169345]

20. Zhang W, Nuki G, Moskowitz RW, Abramson S, Altman RD, Arden NK, Bierma-Zeinstra S, Brandt KD, Croft P, Doherty M, Dougados M, Hochberg M, Hunter DJ, Kwoh K, Lohmander LS, Togwell P. OARSI recommendations for the management of hip and knee osteoarthritis: part III: Changes in evidence following systematic cumulative update of research published through January 2009. Osteoarthritis Cartilage. 2010; 18:476-499. [PubMed: 20170770]

21. Zhang W, Moskowitz RW, Nuki G, Abramson S, Altman RD, Arden N, Bierma-Zeinstra S, Brandt KD, Croft P, Doherty M, Dougados M, Hochberg M, Hunter DJ, Kwoh K, Lohmander LS, Togwell P. OARSI recommendations for the management of hip and knee osteoarthritis, Part II: OARSI evidence-based, expert consensus guidelines. Osteoarthritis Cartilage. 2008; 16:137-162. [PubMed: 18279766]

22. Brouwer RW, Jakma TS, Verhagen AP, Verhaar JA, Bierma-Zeinstra SM. Braces and orthoses for treating osteoarthritis of the knee. Cochrane Database Syst Rev. 2005; (1):CD004020. [PubMed: 15674927]

23. Ramsey DK, Briem K, Axe MJ, Snyder-Mackler L. A mechanical theory for the effectiveness of bracing for medial compartment osteoarthritis of the knee. J Bone Joint Surg Am. 2007; 89:23982407. [PubMed: 17974881]

24. Rannou F, Dimet J, Boutron I, Baron G, Fayad F, Macé Y, Beaudreuil J, Richette P, Ravaud P, Revel M, Poiraudeau S. Splint for base-of-thumb osteoarthritis: a randomized trial. Ann Intern Med. 2009; 150:661-669. [PubMed: 19451573]

25. Kemp G, Crossley KM, Wrigley TV, Metcalf BR, Hinman RS. Reducing joint loading in medial knee osteoarthritis: shoes and canes. Arthritis Rheum. 2008; 59:609-614. [PubMed: 18438932]

26. Fransen M, McConnell S, Bell M. Therapeutic exercise for people with osteoarthritis of the hip or knee. A systematic review. J Rheumatol. 2002; 29:1737-1745. [PubMed: 12180738] 
27. Pisters MF, Veenhof C, Schellevis FG, De Bakker DH, Dekker J. Long-term effectiveness of exercise therapy in patients with osteoarthritis of the hip or knee: a randomized controlled trial comparing two different physical therapy interventions. Osteoarthritis Cartilage. 2010; 18:10191026. [PubMed: 20488250]

28. Thomas KS, Muir KR, Doherty M, Jones AC, O’Reilly SC, Bassey EJ. Home based exercise programme for knee pain and knee osteoarthritis: randomised controlled trial. BMJ. 2002; 325:752. [PubMed: 12364304]

29. Kawasaki T, Kurosawa H, Ikeda H, Takazawa Y, Ishijima M, Kubota M, Kajihara H, Maruyama Y, Kim SG, Kanazawa H, Doi T. Therapeutic home exercise versus intraarticular hyaluronate injection for osteoarthritis of the knee: 6-month prospective randomized open-labeled trial. J Orthop Sci. 2009; 14:182-191. [PubMed: 19337810]

30. Atamaz FC, Durmaz B, Baydar M, Demircioglu OY, Iyiyapici A, Kuran B, Oncel S, Sendur OF. Comparison of the efficacy of transcutaneous electrical nerve stimulation, interferential currents, and shortwave diathermy in knee osteoarthritis: a double-blind, randomized, controlled, multicenter study. Arch Phys Med Rehabil. 2012; 93:748-756. [PubMed: 22459699]

31. Pemberton, R. Arhtirits and rheumatoid conditions: their nature and treatment. Philadelphia: Lea and Febiger; 1935.

32. Ropes, MW.; Bauer, W. Synovial fluid changes in joint disease. Cambridge, MA: Harvard University Press; 1953.

33. Balint PV, Kane D, Hunter J, McInnes IB, Field M, Sturrock RD. Ultrasound guided versus conventional joint and soft tissue fluid aspiration in rheumatology practice: a pilot study. $\mathrm{J}$ Rheumatol. 2002; 29:2209-2213. [PubMed: 12375335]

34. Raza K, Lee CY, Pilling D, Heaton S, Situnayake RD, Carruthers DM, Buckley CD, Gordon C, Salmon M. Ultrasound guidance allows accurate needle placement and aspiration from small joints in patients with early inflammatory arthritis. Rheumatology (Oxford). 2003; 42:976-979. [PubMed: 12730511]

35. Cunnington J, Marshall N, Hide G, Bracewell C, Isaacs J, Platt P, Kane D. A randomized, doubleblind, controlled study of ultrasound-guided corticosteroid injection into the joint of patients with inflammatory arthritis. Arthritis Rheum. 2010; 62:1862-1869. [PubMed: 20222114]

36. Hollander JL, Brown EM Jr, Jessar RA, Brown CY. Hydrocortisone and cortisone injected into arthritic joints; comparative effects of and use of hydrocortisone as a local antiarthritic agent. JAMA. 1951; 147:1629-1635.

37. Centeno LM, Moore ME. Preferred intraarticular corticosteroids and associated practice: a survey of members of the American College of Rheumatology. Arthritis care Res. 1994; 7:151-155. [PubMed: 7727555]

38. Balazs, E. The physical properties of synovial fluid and the specific role of hyaluronic acid. In: Helfet, AJ., editor. Disorders of the Knee. Philadelphia: J B Lippincott; 1982. p. 61-74.

39. Bellamy N, Campbell J, Robinson V, Gee T, Bourne R, Wells G. Viscosupplementation for the treatment of osteoarthritis of the knee. Cochrane Database Syst Rev. 2006; (2):CD005321. [PubMed: 16625635]

40. Migliore A, Tormenta S, Massafra U, Carloni E, Padalino C, Iannessi F, Alimonti A, Martin LS, Granata M. Repeated ultrasound-guided intra-articular injections of $40 \mathrm{mg}$ of Hyalgan may be useful in symptomatic relief of hip osteoarthritis. Osteoarthritis Cartilage. 2005; 13:1126-1127. [PubMed: 16242357]

41. Sun SF, Hsu CW, Sun HP, Chou YJ, Li HJ, Wang JL. The effect of three weekly intra-articular injections of hyaluronate on pain, function, and balance in patients with unilateral ankle arthritis. $\mathrm{J}$ Bone Joint Surg Am. 2011; 93:1720-1726. [PubMed: 21938376]

42. Berenbaum F, Grifka J, Cazzaniga S, D'Amato M, Giacovelli G, Chevalier X, Rannou F, Rovati LC, Maheu E. A randomised, double-blind, controlled trial comparing two intra-articular hyaluronic acid preparations differing by their molecular weight in symptomatic knee osteoarthritis. Ann Rheum Dis. 2012; 71:1454-1460. [PubMed: 22294639]

43. Bannuru RR, Natov NS, Obadan IE, Price LL, Schmid CH, McAlindon TE. Therapeutic trajectory of hyaluronic acid versus corticosteroids in the treatment of knee osteoarthritis: a systematic review and meta-analysis. Arthritis Rheum. 2009; 61:1704-1711. [PubMed: 19950318] 
44. Sluijter ME, Teixeira A, Serra V, Balogh S, Schianchi P. Intra-articular application of pulsed radiofrequency for arthrogenic pain--report of six cases. Pain Pract. 2008; 8:57-61. [PubMed: 18211593]

45. Rohof OJ. Radiofrequency treatment of peripheral nerves. Pain Pract. 2002; 2:257-260. [PubMed: 17147740]

46. Shah RV, Racz GB. Pulsed mode radiofrequency lesioning of the suprascapular nerve for the treatment of chronic shoulder pain. Pain Physician. 2003; 6:503-506. [PubMed: 16871304]

47. Liliang PC, Lu K, Liang CL, Tsai YD, Hsieh CH, Chen HJ. Pulsed radiofrequency lesioning of the suprascapular nerve for chronic shoulder pain: a preliminary report. Pain Med. 2009; 10:70-75. [PubMed: 19222771]

48. Wu H, Groner J. Pulsed radiofrequency treatment of articular branches of the obturator and femoral nerves for management of hip joint pain. Pain Pract. 2007; 7:341-344. [PubMed: 17986165]

49. Moseley JB, O’Malley K, Petersen NJ, Menke TJ, Brody BA, Kuykendall DH, Hollingsworth JC, Ashton CM, Wray NP. A controlled trial of arthroscopic surgery for osteoarthritis of the knee. New Engl J Med. 2002; 347:81-88. [PubMed: 12110735]

50. Kalunian KC, Moreland LW, Klashman DJ, Brion PH, Concoff AL, Myers S, Singh R, Ike RW, Seeger LL, Rich E, Skovron ML. Visually-guided irrigation in patients with early knee osteoarthritis: a multicenter randomized, controlled trial. Osteoarthritis Cartilage. 2000; 8:412418. [PubMed: 11069725]

51. Felson DT, Buckwalter J. Debridement and lavage for osteoarthritis of the knee. New Engl J Med. 2002; 347:132-133. [PubMed: 12110742]

52. Rand JA. Role of arthroscopy in osteoarthritis of the knee. Arthroscopy. 1991; 7:358-363. [PubMed: 1755883]

53. Weinstein JN, Tosteson TD, Lurie JD, Tosteson A, Blood E, Herkowitz H, Cammisa F, Albert T, Boden SD, Hilibrand A, Goldberg H, Berven S, An H. Surgical versus nonoperative treatment for lumbar spinal stenosis four-year results of the Spine Patient Outcomes Research Trial. Spine. 2010; 35:1329-1338. [PubMed: 20453723]

54. Saltzman CL, Salamon ML, Blanchard GM, Huff T, Hayes A, Buckwalter JA, Amendola A. Epidemiology of ankle arthritis: report of a consecutive series of 639 patients from a tertiary orthopaedic center. Iowa Orthop J. 2005; 25:44-46. [PubMed: 16089071]

55. Jackson RW. Surgical treatment. Osteotomy and unicompartmental arthroplasty. Am J Knee Surg. 1998; 11:55-57. [PubMed: 9533056]

56. Kiebzak GM, Vain PA, Gregory AM, Mokris JG, Mauerhan DR. SF-36 general health status survey to determine patient satisfaction at short-term follow-up after total hip and knee arthroplasty. J South Orthop Assoc. 1997; 6:169-172. [PubMed: 9322195]

57. Katz JN, Mahomed NN, Baron JA, Barrett JA, Fossel AH, Creel AH, Wright J, Wright EA, Losina E. Association of hospital and surgeon procedure volume with patient-centered outcomes of total knee replacement in a population-based cohort of patients age 65 years and older. Arthritis Rheum. 2007; 56:568-574. [PubMed: 17265491]

58. Mancuso CA, Salvati EA. Patients' satisfaction with the process of total hip arthroplasty. J Healthcare Qual. 2003; 25:12-18. quiz 8-9.

59. Kirwan JR, Currey HL, Freeman MA, Snow S, Young PJ. Overall long-term impact of total hip and knee joint replacement surgery on patients with osteoarthritis and rheumatoid arthritis. Br J Rheumatol. 1994; 33:357-360. [PubMed: 8156309] 